\title{
Application of Raman Micro Spectroscopy and Micro-FTIR Mapping in the Bio- Hydrometallurgy of Copper Sulfide-Minerals
}

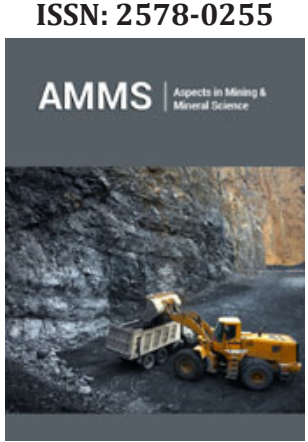

*Corresponding author: Constantinos Varotsis, Department of Chemical Engineering, Cyprus University of Technology, Eirinis 95, Limassol, Cyprus

Submission: 棒April 13, 2020

Published: 䟧June 10, 2020

Volume 5 - Issue 1

How to cite this article: Varotsis $C$, Papageorgiou M, Tselios C, Yiannakkos KA, Adamou A, Nicolaides A. Application of Raman Micro Spectroscopy and MicroFTIR Mapping in the Bio-Hydrometallurgy of Copper Sulfide-Minerals. Aspects Min Miner Sci. 5(1). AMMS.000603. 2020. DOI: 10.31031/AMMS.2020.05.000603

Copyright@ Varotsis C, This article is distributed under the terms of the Creative Commons Attribution 4.0 International License, which permits unrestricted use and redistribution provided that the original author and source are credited.

\author{
Varotsis C*, Papageorgiou M, Tselios C, Yiannakkos KA, Adamou A and \\ Nicolaides A \\ Department of Chemical Engineering, Cyprus University of Technology, Cyprus
}

\section{Abstract}

A combined application of $\mu \mathrm{m}$-FTIR mapping and Raman microspectroscopy for the bioleaching behaviour of copper sulfide minerals such as chalcopyrite, bornite, chalcocite and covellite provides valuable information on the whole bio-hydrometallurgy $\mathrm{Cu} / \mathrm{Fe} / \mathrm{S}$ system. Both techniques provide labelfree, nondestructive visualizations of the bio-hydrometallurgy dynamics for processing and storage of large spectral data sets which are valuable for evaluation of copper, iron and sulfur containing minerals. The results provide solid evidence that the techniques can be also applied to other Bio-hydrometallurgical extracted metals from Polymetallic Mineral Resources.

Keywords: Micro spectroscopy; Minerals; Metal ions; Copper

\section{Introduction}

New methods for maximizing copper extraction from whole ores and processing tails and sensory technologies for daily monitoring have been developed (Figure ${ }^{1}$ ). Heap bioleaching is the most applicable technology to treat low grade copper sulfide ores and bearing chalcopyrite, idaite, bornite, chalcocite and covellite. A variety of biochemical processes in conjunction with state-of-the-art sensory technologies have been applied towards establishing the Biohydrometallurgy treatment of low-grade copper mixed ores and mineral processing tails [1,2]. High copper extractions are achieved with isolated and mixed cultures of the mesophilic iron and sulfur oxidizing bacteria Acidithiobacillus ferroxidans and Acidithiobacillus thiooxidans, and in the presence of moderately thermophilic microorganisms such as Acidithiobacillus caldus, Leptospirillum ferriphilum and their mixed cultures [1,2]. The elucidation of the mechanisms involved in the interactions of sulfur oxidizing bacteria with the mixed ores in the bioleaching procedure is important for understanding the bioleaching behavior between single and mixed ores and the origin of the existing differences [1,2]. Oxidation-reduction potential, temperature, $\mathrm{pH}$ and the origin of the microorganisms are crucial in our understanding the whole bio-hydrometallurgy system. Chalcopyrite $\left[\mathrm{CuFeS}_{2}\right]$ is the most abundant copper sulfide ore that has received extensive attention because there are considerable ore reserves that could be exploited. It has been suggested that the primary oxidation product of chalcopyrite leaching is chalcocite which is subsequently oxidized to covellite [2].The formation of the latter is confirmed by ore microscopy and by a number of structure sensitive techniques such as Raman and FTIR [1,2]. Raman spectra including the images can provide the information for identification of surface species/phases and spatial variations in composition of the bioleaching of chalcopyrite as well the formation of the passivation layers in $\mathrm{Cu} / \mathrm{Fe} / \mathrm{S}$ and $\mathrm{Cu} / \mathrm{S}$ systems. (Figure ${ }^{2}$ ) spectrum A, shows the Raman spectra of bornite and the 1-6 months bioleached bornite samples by a consortium of microorganisms consisted of Acidithiobacillus ferrooxidans, Acidithiobacillus thiooxidans, Acidithiobacillus caldus, Leptospirillum ferriphilum, Leptospirillum ferroodiazotrophum and Sulfobacillus thermosulfidooxidans. In the one month bioleaching period (spectrum A) there are several new Raman bands including those at 220 and $430 \mathrm{~cm}^{-1}$ which we assign to the $v(\mathrm{Fe}-\mathrm{O})$ of $\mathrm{K}^{+}$- jarosite respectively. We also assign the bands at $450,624,1004,1097$, and $1157 \mathrm{~cm}^{-1}$ to $v_{2}\left(\mathrm{SO}_{4}{ }^{2-}\right), v_{4}\left(\mathrm{SO}_{4}{ }^{2-}\right), v_{1}\left(\mathrm{SO}_{4}{ }^{2-}\right), v_{3}\left(\mathrm{SO}_{4}{ }^{2-}\right)$ and $v_{3}\left(\mathrm{SO}_{4}\right)^{2-}$ of $\mathrm{K}^{+}$- jarosite, respectively. The marker band in the Raman data for distinguishing the $\mathrm{K}^{+}$from $\mathrm{NH}_{4}^{+}$jarosite is the $v_{3}\left(\mathrm{SO}_{4}^{2-}\right)$ vibration observed at $1099 \mathrm{~cm}^{-1}$ in the spectra of 
$\mathrm{K}^{+}$- jarosite and at $1091 \mathrm{~cm}^{-1}$ in the spectrum of $\mathrm{NH}_{4}{ }^{+}$-jarosite. The absence of $\mathrm{NH}_{4}{ }^{+}$marker bands in the spectrum strongly suggests that in one month period only $\mathrm{K}^{+}$- jarosite is formed. The strong band at $473 \mathrm{~cm}^{-1}$ is attributed to $v(\mathrm{Cu}-\mathrm{S})$ of covellite. Elemental sulphur and polysulfides contain S-S linkages and display the $v(\mathrm{~S}-\mathrm{S})$ and $\delta(\mathrm{S}-\mathrm{S}-\mathrm{S})$ which are characterized by equally strong intensities at 470 at $215 \mathrm{~cm}^{-1}$, respectively. The intensity of the $v(\mathrm{~S}-\mathrm{S}) / \delta(\mathrm{S}-\mathrm{S}-\mathrm{S})$ ratio has been applied used to distinguish the elemental sulphur from the other S-S and Cu-S bond containing species. At six months (spectrum B), the $220 \mathrm{~cm}^{-1}$ band attributed to $\mathrm{K}^{+}$- jarosite has shifted to $218 \mathrm{~cm}^{-1}$ and gained intensity which is attributed to the formation of $\delta(\mathrm{S}-\mathrm{S}-\mathrm{S})$ of elemental sulphur. Given that the $v(\mathrm{~S}-\mathrm{S})$ and $\delta(\mathrm{S}-\mathrm{S}-\mathrm{S})$ are characterized by equally strong intensities we suggest that the band at $473 \mathrm{~cm}^{-1}$ has little contribution from the $v(\mathrm{Cu}-\mathrm{S})$, and thus, we attributed it to $v(\mathrm{~S}-\mathrm{S})$ of elemental sulphur. This observation indicates that at six-months of bioleaching, the
$474 \mathrm{~cm}^{-1}$ covellite band observed in spectrum A has disappeared. In addition, all bands attributed to $\mathrm{K}^{+}$- jarosite including the $v(\mathrm{Fe}-\mathrm{O})$ at $430 \mathrm{~cm}^{-1}$ have lost most of their peak intensity, and in contrast to the bioleaching behaviour of chalcopyrite, there is no evidence for the formation of $\mathrm{NH}_{4}^{+}$- jarosite. Studies examining the dissolution behaviour of $\mathrm{K}^{+}$, and $\mathrm{NH}_{4}^{+}$- jarosites from the ore surface are limited. It is intriguing to propose that in our study more than one microorganism was involved in the biosynthesis of $\mathrm{K}^{+}$- jarosite. The presence of $\mathrm{K}^{+}$- jarosite at one month period and the lack of $\mathrm{NH}_{4}^{+}$- jarosite formation suggest that $\mathrm{K}^{+}$- jarosite is not subject to microbial reduction leading to intermediate mineral of the microbial process. In addition, the behavior of the $\mathrm{K}^{+}$- jarosite marker bands at six months period indicates that either its presence is reduced substantially because it has broken down by converting to iron (III) oxide or oxyhydroxide phases or that is not part of the surface of the bioprocessed mineral, and thus, not detectable.
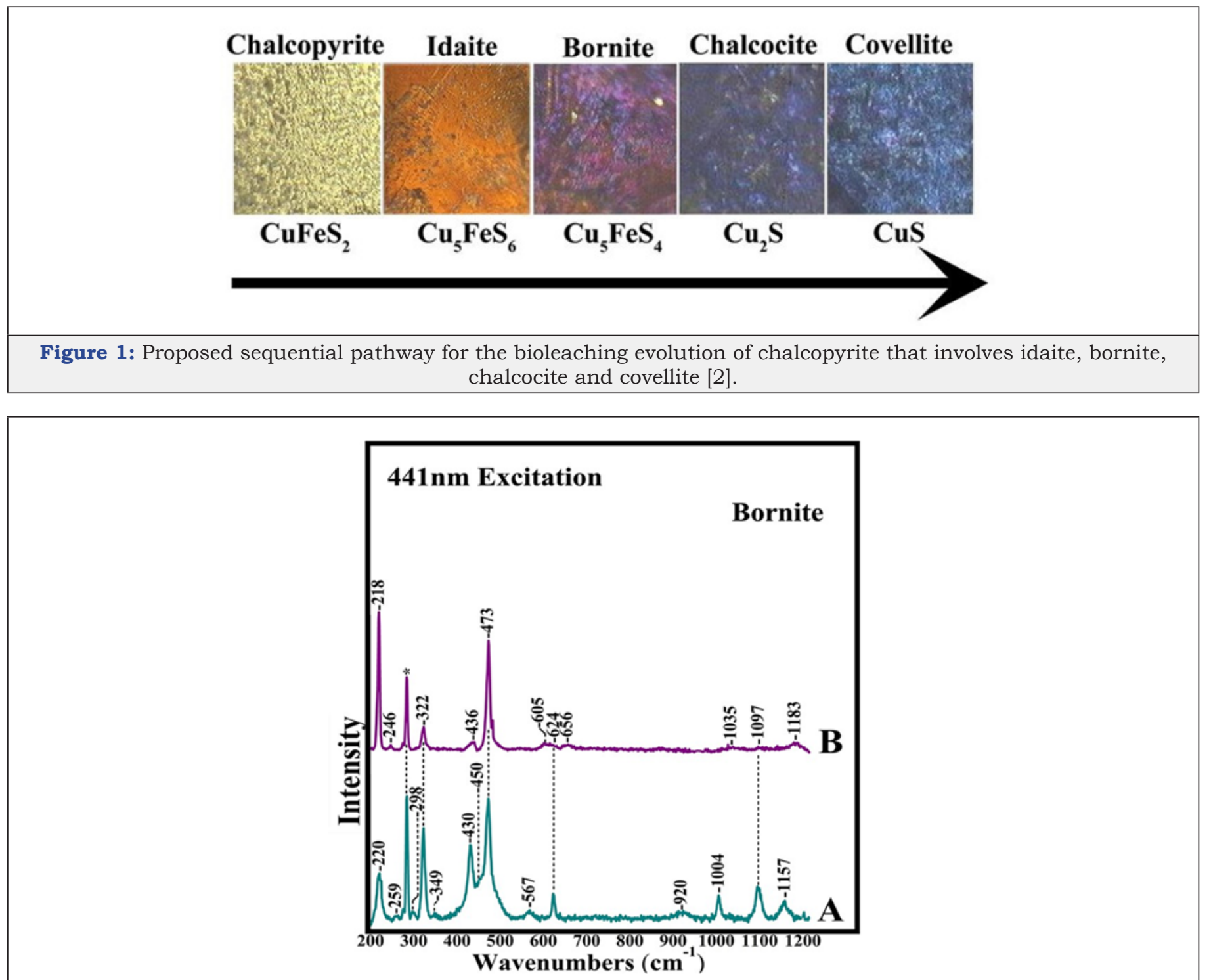

Figure 2: Raman spectra of bioleached bornite samples. The consortium of microorganisms consisted of Acidithiobacillus ferrooxidans, Acidithiobacillus ferrooxidans, Acidithiobacillus ferrooxidans, Leptospirillum ferriphilum, Leptospirillum ferroodiazotrophum and Sulfobacillus thermosulfidooxidans. Spectra A and B are at one and six months of bioleaching period, respectively. 
Bioleaching of $\mathrm{Cu} / \mathrm{Fe} / \mathrm{S}$ minerals also leads to precipitation of Fe(III) hydroxysulfates and metal- deficient passivating layers which dramatically decrease the access of leaching agents and bacteria cells to the mineral surfaces, making the bioleaching procedure still not optimized and fully successful. FTIR imaging spectroscopy has been applied to monitor the formation of jarosite passivation layers which are of profound importance because despite great efforts, researchers have not reached a consensus on the control steps governing whole ore bioleaching [1,2]. Potassium Jarosite $\left[\mathrm{KFe}_{3}\left(\mathrm{SO}_{4}\right)_{2}(\mathrm{OH})_{6}\right]$ is a mineral that is common in acidic, sulfate-rich environments, such as acid sulfate soils derived from pyrite-bearing sediments, weathering zones of sulfide ore deposits and acid mine rock drainage (ARD/AMD) sites. Jarosite typically is formed in ferric rich, acidic $(\mathrm{pH}<3)$ oxic environments and readily breaks down when removed from its stability region by presumably converting to iron (III) oxide or oxyhydroxide phases. $\mathrm{K}^{+}(\mathrm{aq})$ jarosite converts to goethite through the following reaction

$\mathrm{KFe}_{3}\left(\mathrm{SO}_{4}\right)_{2}(\mathrm{OH})_{6}(\mathrm{~S}) \leftrightarrow 3 \mathrm{FeO}(\mathrm{OH})$ Geothite $+\mathrm{K}^{+}(a q)+2 \mathrm{SO}_{4}^{2-}(a q)+3 \mathrm{H}^{+}(a q)$

Bacterial cell finds a way to protect itself from the infiltration of toxic metal ions by covering its peripheral surface with a shield of EPS. Structural and compositional makeup of EPS favors the sequestration of metal ions and hence obstructs them from penetrating the cell surface. The mixed culture microbial biofilms and their extracellular polymeric substances associated with the solid-liquid interfaces have several key properties and functions. A close inspection of the intensity of the respective peaks in the 1000$1200 \mathrm{~cm}^{-1}$ region in the FTIR spectra illustrated that the relative contents of chemical groups are distinctly different between bornite, chalcocite and covellite [1,2]. The mixed culture biofilms are spatially structured communities of microbes whose function is dependent upon a complex web of symbiotic interactions. Apart from cellular constituents, a major component of biofilm systems is the EPS produced by the members. The extracellular polymeric substances (EPS) of the biofilm matrix appear to have several key properties and functions. Extracellular polymeric substances (EPS) are complex high molecular weight microbial biopolymers which occur in a range of molecular sizes, conformations and physicochemical properties, and polysaccharides, proteins, lipids, and even nucleic acids are actively secreted components. The physical ultrastructure of how individual EPS interact with each other is poorly understood. The major components present in EPS are proteins, polysaccharides, uronic acids, lipids and humic substances. Little is known about the mineral-humic substances interactions. One of its essential constituent is the exopolysaccharide (EPS) released out of self defence against harsh conditions of starvation, $\mathrm{pH}$ and temperature, hence it displays physiological, rheological and physico-chemical properties (Figure ${ }^{3}$ ).

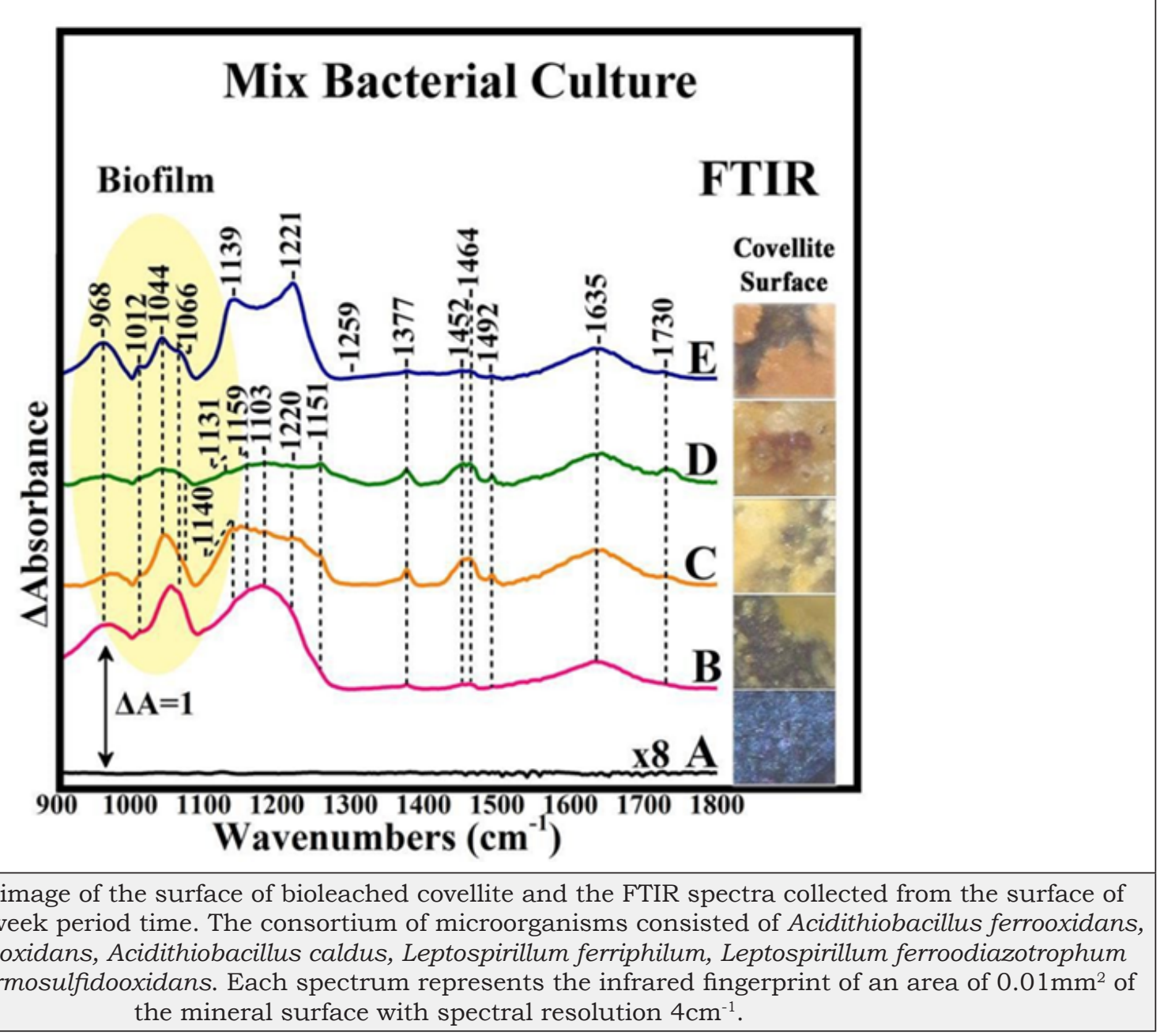


The FTIR analysis was carried out to probe the chemical structures of the various mixed culture biofilms and their EPS on the surfaces of covellite. The positions and number of FTIR peaks for the different biofilms and EPS appeared to be quite different, implying that the types of chemical groups involved are quite different. Several strong bands associated with proteins and polysaccharides were observed in the marker bands, among which are the stretching vibration $\mathrm{C}=\mathrm{O}\left(1637 \mathrm{~cm}^{-1}\right)$ and the $\mathrm{C}-\mathrm{O}-\mathrm{C}$ stretching vibration of polysaccharides $\left(960-1150 \mathrm{~cm}^{-1}\right)[1,2]$. The intensity and peak positions in the $\mu \mathrm{m}$-FTIR data clearly demonstrated that the relative contents of chemical groups are distinctly different. These observations demonstrate that the biofilms and the associated EPS consisted of different components. On the mechanism of EPS attachment on the mineral, the most reasonable interpretation is that charge effects are involved whereas molecules acting as Lewis acids by accepting electrons from the mineral-sulfur, like EPS-complexed iron species, will preferentially strongly attracted. The selective attachment to mineral ores is associated with the occurrence of distinct dislocation sited, where sulphur atoms are accumulated.

\section{Conclusion}

Raman microspectroscopy and micro-FTIR mapping/ imaging are structure sensitive techniques that have been applied successfully in our laboratory for over 30 years towards our understanding of the characterization of the structure-function relationship in biomolecules, and recently in minerals, and in monitoring the steps governing whole ore bioleaching [1-14]. FTIR is well established as a method for studying solid state transformations in minerals and bio minerals and micro-FTIR extends this functionality to include spectroscopic mapping at the micrometer length scale. The achievement of chemical and structural mapping of (bio)-minerals opens new horizons for our understanding of mineral arrangements and variability in biological systems. Based on our results we propose a mechanism for the sequential steps for chalcopyrite bioleaching in which chalcopyrite is converted initially to $\mathrm{Cu}_{2} \mathrm{~S}$, and subsequently to $\mathrm{CuS}$. $\mathrm{K}^{+}$- jarosite formation is not followed by the formation of $\mathrm{NH}_{4}^{+}$ jarosite as it was observed in the case of chalcopyrite. The role of the microenvironment filled with EPS which contains sugars, fatty acids and lipids and formed between the bacterium and the metal sulfide surface is distinct in each case. The dynamics of the EPS which are essential for cell attachment and metal sulfide leaching is time-dependent.

\section{Acknowledgement}

Financial support by the European Regional Development Fund and the Republic of Cyprus through the Research Promotion Foundation (Grant No ENTERPRISES/0916/0069) is gratefully acknowledged.

\section{References}

1. Adamou A, Manos G, Messios N, Georgiou L, Xydas C, et al. (2016) Probing the whole ore chalcopyrite-bacteria interactions and jarosite biosynthesis by Raman and FTIR microspectroscopies. Bioresour Technol 214: 852-855.

2. Adamou A, Nicolaides A, Varotsis C (2019) Bio-hydrometallurgy dynamics of copper sulfide- minerals probed by micro-FTIR mapping and Raman microspectroscopy. Minerals Engineering 132: 39-47.

3. Pinakoulaki E, Varotsis C (2008) Nitric oxide activation and reduction by heme-copper oxidoreductases and nitric oxide reductase. J Inorg Biochem 102(5-6): 1277-1287.

4. Pinakoulaki E, Varotsis C (2003) Time-resolved resonance raman and time-resolved step-scan FTIR studies of nitric oxide reductase from Paracoccus denitrificans: Comparison of the heme $\mathrm{b}_{3}-\mathrm{FeB}$ site to that of the heme-CuB in oxidases. Biochemistry 42(50): 14856- 14861.

5. Varotsis C, Woodruff WH, Babcock GT (1990) Time-resolved Raman detection of .mu.(Fe-O) in an early intermediate in the reduction of oxygen by cytochrome oxidase. Journal of the American Chemical Society 112(3): 1297-1297.

6. C Koutsoupakis, Pinakoulaki E, Stavrakis S, Daskalakis V, Varotsis C (2004) Time-resolved step-scan Fourier transform infrared investigation of heme-copper oxidases: implications for $\mathrm{O}_{2}$ input and $\mathrm{H}_{2} \mathrm{O} / \mathrm{H}^{+}$output channels. Biochimica et Biophysica Acta (BBA)-Bioenergetics 1655(13): 347-352.

7. Iwase T, Varotsis C, Shinzawa Itoh K, Yoshikawa S, Kitagawa T (1999) Infrared evidence for $\mathrm{CuB}$ ligation of photodissociated $\mathrm{CO}$ of cytochrome $\mathrm{c}$ oxidase at ambient temperatures and accompanied deprotonation of a carboxyl side chain of protein. Journal of the American Chemical Society 121(6): 1415-1416.

8. Pinakoulaki E, Ohta T, Soulimane T, Kitagawa T, Varotsis C (2004) Simultaneous resonance raman detection of the heme $\mathrm{a}_{3}-\mathrm{Fe}-\mathrm{CO}$ and

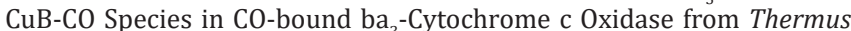
thermophilus evidence for a charge transfer CUB CO Transition. Journal of Biological Chemistry 279(22): 22791-22794.

9. Koutsoupakis C, Soulimane T, Varotsis C (2003) Docking site dynamics of $\mathrm{ba}_{3}$-cytochrome c oxidase from Thermus thermophiles. Journal of Biological Chemistry 278(38): 36806-36809.

10. Stavrakis S, Pinakoulaki E, Urbani A, Varotsis C (2002) Fourier transform infrared evidence for a ferric six-coordinate nitrosylheme $b_{3}$ complex of cytochrome $\mathrm{cbb}_{3}$ oxidase from Pseudomonas stutzeri at ambient temperature. The Journal of Physical Chemistry B 106(50): 1286012862.

11. Varotsis C, Vamvouka M (1999) Resonance raman and fourier transform infrared detection of azide binding to the binuclear center of cytochrome $\mathrm{bo}_{3}$ oxidase from Escherichia coli. The Journal of Physical Chemistry B 103(19): 3942-3946

12. Babcock GT, Varotsis C, Zhang Y (1992) $\mathrm{O}_{2}$ activation in cytochrome oxidase and in other heme proteins. Biochimica et Biophysica Acta (BBA)-Bioenergetics 1101(2): 192-194.

13. Pinakoulaki E, Yoshimura H, Yoshioka S, Aono S, Varotsis C (2006) Recognition and discrimination of gases by the oxygen-sensing signal transducer protein HemAT as revealed by FTIR spectroscopy. Biochemistry 45(25): 7763-7766.

14. Ohta T, Pinakoulaki E, Soulimane T, Kitagawa T, Varotsis C (2004) Detection of a photostable five-coordinate heme $\mathrm{a}_{3}-\mathrm{Fe}-\mathrm{CO}$ species and functional implications of His384/ $\alpha 10$ in CO- bound ba $\mathrm{b}_{3}$-cytochrome c oxidase from Thermus thermophiles. The Journal of Physical Chemistry B 108(18): 5489-5491.

For possible submissions Click below: 